\title{
Rapid, sensitive and effective diagnostic tools for foot- and-mouth disease virus in Africa
}

\author{
Authors: \\ Christopher J. Kasanga \\ Wataru Yamazaki² \\ Valerie Mioulet $^{3}$ \\ Donald P. King ${ }^{3}$ \\ Misheck Mulumba ${ }^{4}$ \\ Ezekia Ranga ${ }^{6}$ \\ Jimis Deve ${ }^{7}$ \\ Cornelius Mundia ${ }^{8}$ \\ Patrick Chikungwa ${ }^{9}$ \\ Laureta Joao ${ }^{10}$ \\ Philemon N. Wambura ${ }^{5}$ \\ Mark M. Rweyemamu

\section{Affiliations:} \\ ${ }^{1}$ Southern African Centre \\ for Infectious Disease \\ Surveillance, Sokoine \\ University of Agriculture, \\ Tanzania
}

${ }^{2}$ Department of Microbiology, University of Miyazaki, Japan

${ }^{3}$ The Pirbright Institute,

United Kingdom

${ }^{4}$ Southern African

Development Community

Secretariat, Botswana

${ }^{5}$ Faculty of Veterinary

Medicine, Sokoine University

of Agriculture, Tanzania

${ }^{6}$ Ministry of Livestock

Development and Fisheries,

Tanzania

${ }^{7}$ Southern African

Development Community,

Transboundary Animal

Diseases Section,

Mozambique

${ }^{8}$ Southern African

Development Community,

Transboundary Anima

Diseases Section, Zambia

${ }^{9}$ Southern African

Development Community,

Transboundary Animal

Diseases Section, Malawi

${ }^{10}$ Southern African

Development Community,

Transboundary Animal

Diseases Section, Angola

Correspondence to:

Christopher Kasanga

\section{Read online:}

Speed is paramount in the diagnosis of highly infectious diseases, such as foot-and-mouth disease (FMD), as well as for emerging diseases; however, simplicity is required if a test is to be deployed in the field. Recent developments in molecular biology have enabled the specific detection of FMD virus (FMDV) by reverse-transcription loop-mediated isothermal amplification (RT-LAMP), real-time reverse-transcription polymerase chain reaction (RTqPCR) and sequencing. RT-LAMP enables amplification of the FMDV RNA-dependent RNA polymerase $3 \mathrm{D}(\mathrm{pol})$ gene at $63{ }^{\circ} \mathrm{C}$ (in the presence of a primer mixture and both reverse transcriptase and Bst DNA polymerase) for $1 \mathrm{~h}$, whilst RT-qPCR amplifies the same gene in approximately $2 \mathrm{~h} 30 \mathrm{~min}$. In this study, we compared the sensitivity and effectiveness of RT-LAMP against RT-qPCR for the detection of the FMDV 3D(pol) gene in 179 oesophagealpharyngeal scraping samples (collected by probang) obtained from clinically healthy cattle and buffalo in Malawi, Mozambique and Tanzania in 2010. The FMDV detection rate was higher with RT-LAMP $(30.2 \% ; n=54)$ than with RT-qPCR $(17.3 \% ; n=31)$. All samples positive by RT-qPCR $(\mathrm{Cq} \leq 32.0)$ were also positive for the RT-LAMP assay; and both assays proved to be highly specific for the FMDV target sequence. In addition, the VP1 sequences of 10 viruses isolated from positive samples corresponded to the respective FMDV serotypes and genotypes. Our findings indicate that the performance of RT-LAMP is superior to RT-qPCR. Accordingly, we consider this test to have great potential with regard to the specific detection and surveillance of infectious diseases of humans and animals in resource-compromised developing countries.

\section{Introduction}

Foot-and-mouth disease (FMD) is a highly contagious disease that affects cloven-hooved animals such as cattle, sheep, goats and pigs. FMD outbreaks have occured worldwide, resulting in significant economic losses (Knowles \& Samuel 2003). Early identification of FMD virus (FMDV) is, therefore, critical for the control of disease and to minimise losses that could occur in livestock. Rapid and accurate diagnosis of FMDV is required for effective disease control. FMD cannot be distinguished clinically from other vesicular diseases, such as swine vesicular disease (SVD), vesicular exanthema of swine (VES) and vesicular stomatitis (VS); similarities that can pose challenges for early confirmation of field outbreaks. Routine laboratory diagnosis of FMD can be performed by a combination of antigen-capture enzyme-linked immunosorbent assay (ELISA) and virus isolation (OIE 2012). Antigen-capture ELISA only takes $4 \mathrm{~h}$ to perform; however, this test is only suitable for epithelium samples and does not have the analytical sensitivity required to confirm the negative status of premises (OIE 2012; Reid et al. 2001). In contrast, viral isolation is highly sensitive, but can take long time: up to two weeks to deliver a definitive answer. Several reverse-transcription polymerase chain reaction (RT-PCR) and real-time RTPCR (RT-qPCR) assays have been developed for the detection of FMDV (Callahan et al. 2002; Reid et al. 2000, 2001). RT-qPCR assays, which are highly sensitive and rapid and do not require electrophoresis, are now used widely for routine diagnosis of FMDV (Reid et al. 2009; Shaw et al. 2007). However, because these assays require a precision thermal cycler with a fluorescence detector and commercially-available kit-form reagents, these assays can be expensive to perform. Given these limitations, a rapid, simple, sensitive, and more cost-effective assay for diagnosis of FMD in clinical samples is required.

A recently-developed novel nucleic acid amplification method, termed loop-mediated isothermal amplification (LAMP) (Nagamine, Hase \& Notomi 2002), is a promising candidate for rapid and easy detection of FMDV cDNA. LAMP is based on the principle of autocycling strand displacement

\section{Email: christopher.kasanga@sacids.org \\ Postal address: PO Box 3019, Chuo Kikuu, Morogoro, Tanzania}

How to cite this article: Kasanga, C.J., Yamazaki, W., Mioulet, V., King, D.P., Mulumba, M., Ranga, E. et al., 2014, 'Rapid, sensitive and effective diagnostic tools for foot-and-mouth disease virus in Africa', Onderstepoort Journal of Veterinary Research 81(2) Art. \#727, 5 pages. http://dx.doi.org/10.4102/ojvr.v81i2.727

Note: Proceedings of the 2 nd One Health Conference in Africa. Jointly organised by the Southern African Centre for Infectious Disease Surveillance and the Tanzania National Institute for Medical Research, held at the Snow Crest Hotel in Arusha, Tanzania from 16th to 19 th April 2013: http://www.sacids.org/kms/frontend/index.php?m=119.

Copyright: @ 2014. The Authors. Licensee: AOSIS OpenJournals. This work is licensed under the Creative Commons Attribution License. 
DNA synthesis performed by the large fragment of Bst DNA polymerase. A combined mix of AMV reverse transcriptase and Bst DNA polymerase enables simultaneous reverse transcription and DNA amplification to be undertaken in the same tube. Reverse-transcription loop-mediated isothermal amplification (RT-LAMP) assays are known to be more sensitive than conventional gel-based reverse-transcription polymerase chain reaction (RT-PCR) assays. In addition, they are fast and easy to perform since they require only a simple incubator, such as a heating block or a water bath, to provide a constant temperature for the reaction (Parida et al. 2006).

The aim of this study was to assess the performance of RT-qPCR and RT-LAMP assays for detection of the RNAdependent RNA polymerase $3 \mathrm{D}(\mathrm{pol})$ gene of the FMDV genome from oesophageal-pharyngeal (OP) scraping samples (collected by probang) obtained from cattle and buffalo for the purposes of active surveillance.

\section{Research method and design Samples}

Oesophageal-pharyngeal scrapings were collected from clinically healthy cattle and buffalo in Malawi (Lengwe National Park [NP]), Mozambique (Marromeu NP) and Tanzania (Katavi NP) in 2010. The samples were collected in separate vials containing transport media, then were transported to the Food and Agriculture Organization (FAO) World Reference Laboratory for FMD (WRLFMD) at Pirbright and stored at $-20^{\circ} \mathrm{C}$ until use.

\section{RNA extraction}

Total RNA was extracted from $600 \mu \mathrm{L}$ elution buffer-sample mixture $(140 \mu \mathrm{L}$ original OP sample mixed with $460 \mu \mathrm{L}$ elution buffer) using the RNeasy 96 BioRobot 9604 Kit (catalogue number 967142) on an automated robotic platform (MagNA Pure LC, Roche). The resultant total RNA was eluted in $50 \mu \mathrm{L}$ nuclease-free $\mathrm{H}_{2} \mathrm{O}$ and stored in aliquots of $10 \mu \mathrm{L}$ at $-80{ }^{\circ} \mathrm{C}$ until required.

\section{Real-time RT-PCR assay}

An established one-step RT-qPCR specific for the 3D(pol) region of FMDV (Reid et al. 2009, adapted from Callahan et al. 2002) was used in this study.
This one-step real-time RT-PCR assay was performed (in duplicate) using an Mx3005P qPCR system (Stratagene, La Jolla, CA, USA). Briefly, each $25 \mu \mathrm{L}$ PCR reaction contained $0.8 \mu \mathrm{M}$ each of the 3DF/3DR primers $(100 \mu \mathrm{M}$ stock concentration, Applied Biosystems), $0.3 \mu \mathrm{M}$ 3DP TaqMan probe (labelled with FAM and TAMRA as reporter and quencher, respectively) and $0.5 \mu \mathrm{L}$ Superscript III/ Platinum Taq enzyme mix (supplied with the SuperScript ${ }^{\circledR}$ III Platinum ${ }^{\circledR}$ One-Step qRT-PCR Kit; catalogue number 11732-088, Life Technologies, Paisley UK) to amplify $5 \mu \mathrm{L}$ of template RNA. The amplification involved incubation of reverse transcription reactions at $48{ }^{\circ} \mathrm{C}$ for $45 \mathrm{~min}$, then a 10 min denaturation at $95{ }^{\circ} \mathrm{C}$, followed by 50 cycles of $15 \mathrm{~s}$ for denaturation at $95{ }^{\circ} \mathrm{C}$ and $60 \mathrm{~s}$ combined annealing/ extension at $60{ }^{\circ} \mathrm{C}$. Following amplification, quantification cycle $(\mathrm{Cq})$ values were assigned and the average $\mathrm{Cq}$ value of the results from duplicate samples was used for analysis. The primers and probe used are shown in Table 1.

\section{RT-LAMP assay}

Multiplex RT-LAMP assays were performed in a PCR reaction tube(PCRSnapstrip 0.2mLNatural,cataloguenumber 3240-00, Anachem, Luton, UK) as described previously (Yamazaki et al. 2012). Briefly, a $25 \mu \mathrm{L}$ volume reaction mix that contained $2 \mu \mathrm{L}$ template RNA, $0.15 \mathrm{U}$ AMV reverse transcriptase (Invitrogen, Carlsbad, CA, USA), 8 U Bst DNA polymerase (Large Fragment; New England Biolabs, Ipswich, MA, USA), 20 mM Tris- $\mathrm{HCl}$ (pH 8.8, Cambridge Bioscience, Cambridge, UK), $10 \mathrm{mM} \mathrm{KCl}$ (Sigma-Aldrich), $8 \mathrm{mM} \mathrm{MgSO}_{4}$ (New England Biolabs), $10 \mathrm{mM}\left(\mathrm{NH}_{4}\right)_{2} \mathrm{SO}_{4}$ (Sigma-Aldrich), $0.1 \%$ Tween20 (Sigma-Aldrich), $0.8 \mathrm{M}$ Betaine (Sigma-Aldrich), 1.4 $\mu \mathrm{M}$ each dNTP (GE Healthcare, Little Chalfont, UK), $1.6 \mu \mathrm{M}$ each inner primer (8-FIP and 8-BIP), $0.2 \mu \mathrm{M}$ each outer primer (81-F3 and 81-B3) and $0.8 \mu \mathrm{M}$ each loop primer (81-LF and 81-LB). Each RT-LAMP reaction was incubated at $63^{\circ} \mathrm{C}$ for $1 \mathrm{~h}$, followed by $80^{\circ} \mathrm{C}$ for $5 \mathrm{~min}$. Amplified products were detected at $650 \mathrm{~nm}$ using a Loopamp EXIA turbidimeter (Teramecs, Kyoto, Japan). A reaction was considered positive when the differential value of the turbidity reached 0.1 FTU within $1 \mathrm{~h}$. A Tp value (time of positivity, in minutes) was designated as the time at which this differential value reached this threshold. The evaluation of the multiplex RT-LAMP assays was performed using blind coded samples.

TABLE 1: Primers and probes used for one-step RT-qPCR and RT-LAMP for the detection of FMDV.

\begin{tabular}{|c|c|c|c|c|c|}
\hline $\begin{array}{l}\text { Target region for } \\
\text { primers and probes }\end{array}$ & Type of primer or probe & Oligo name & Sequence $\left(5^{\prime}-3^{\prime}\right)$ & Working conc $(\mu \mathrm{M})$ & Gene location \\
\hline \multirow[t]{3}{*}{ FMDV 3D $\dagger$} & Forward primer & Callahan 3DF & ACTGGGTTTTACAAACCTGTGA & 0.8 & $\mathrm{n} / \mathrm{a}$ \\
\hline & Reverse primer & Callahan 3DR & GCGAGTCCTGCCACGGA & 0.8 & $\mathrm{n} / \mathrm{a}$ \\
\hline & TaqMan probe & Callahan 3DP & FAM-TCCTTTGCACGCCGTGGGAC-TAMRA & 0.5 & $\mathrm{n} / \mathrm{a}$ \\
\hline \multirow[t]{6}{*}{ FMDV LAMP $\ddagger$} & Forward primer & $81-\mathrm{F3}$ & GTTGCAACCCTGATGTTGA & 0.2 & $7331-7349$ \\
\hline & Reverse primer & 81-B3 & GGCATGCTCCGTGTTCAC & 0.2 & $7536-7519$ \\
\hline & Forward inner primer & 8-FIP & GTTCATCGCGTCACTGCAGTGTGCTCAGTACAGAAACGTGTG & 1.6 & $7446-7426,7374-7394$ \\
\hline & Reverse inner primer & 8-BIP & ATGTTTGAGGAAGTGTTCCGCACAGAGTCTTCAGGATCCACTC & 1.6 & $7450-7472,7517-7498$ \\
\hline & Loop primer & 81-LF & CATCAAAGGCCGAATAGTCCAC & 0.8 & $7420-7399$ \\
\hline & Loop primer & 8-LB & GACTTCGGCTTCCACCC & 0.8 & $7474-7490$ \\
\hline
\end{tabular}

Source: †Callahan et al. (2002); †̣amazaki et al. (2012)

RT, reverse transcriptase; PCR, polymerase chain reaction; FMDV, foot-and-mouth disease virus; LAMP, loop-mediated isothermal amplification; n/a, Not applicable. 


\section{Specificity of RT-LAMP assay}

The RT-LAMP assay specificity was assessed using samples positive for swine vesicular disease virus (SVDV), vesicular stomatitis virus (VSV) and vesicular exanthema of swine virus (VESV) that cause infections that are clinically indistinguishable from FMD.

\section{Results}

A total number of 179 OP samples were tested for the 3D(pol) region of the FMDV genome by both RT-qPCR and RTLAMP assays. Thirty-one samples (17.3\%) tested positive for FMDV by RT-qPCR whilst 54 samples $(30.2 \%)$ were positive for FMDV by RT-LAMP. The detection rate of FMDV was, on average, three to four times higher in samples collected from buffalo compared with those obtained from cattle in the livestock-wildlife interface areas of Katavi, Lengwe and Marromeu National Parks in Tanzania, Malawi and Mozambique respectively. The summary of results is shown in Table 2.

The multiplex RT-LAMP assay demonstrated higher sensitivity (54/179) in detection of FMDV RNA from OP probang scraping samples than RT-qPCR (31/179). All samples that produced a positive result by RT-qPCR (with $\mathrm{Cq}$ values $\leq 32.0$ ) were positive by RT-LAMP assay. The 23 samples that tested positive by RT-LAMP but negative by RT-qPCR had $\mathrm{Cq}$ values ranging from 32.5 to 38.5. The RT-LAMP assay was shown to be specific for FMDV as all the RNA samples positive for SVDV, VSV and VESV were negative for FMDV. In addition, 10 samples that were positive for FMDV by both RT-LAMP and RT-qPCR were sequenced for the VP1 coding region and all sequences corresponded to the respective serotypes and/or genotypes of the virus.

\section{Ethical considerations}

This study was conducted in accordance with relevant national and international guidelines on handling animals and the ARRIVE guidelines (Kilkenny et al. 2010) for reporting in vivo animal experiments were adhered to.

\section{Trustworthiness}

The experiment was considered to be both reliable and valid. Reliability of the study was tested by repeating the same procedure for RT-LAMP and RT-qPCR on positive control RNA obtained from the reference FMDV isolate O1 Manisa (TUR/8/69), which yielded the same results on repeated trials. The experimental procedures were performed with care and interpretation of results was done according to the established standards.

\section{Discussion}

Rapid, sensitive and specific detection methods for FMDV are necessary for deploying rational control methods for FMD in a specific geographic region. RT-qPCR and RTLAMP are two sensitive and rapid diagnostic methods for FMDV. In contrast to RT-PCR (either real time or gel-based), the design of RT-LAMP assays is particularly challenging because a larger number of oligonucleotides is required in order to perform the test. In this study, the performance of RT-qPCR and RT-LAMP for FMDV detection on OP samples was evaluated. The performance of RT-LAMP was higher $(30.2 \% ; n=54)$ than RT-qPCR $(17.3 \% ; n=31)$ (Table 2). Several studies have shown that the diagnostic sensitivity of RTLAMP assays for FMDV is high, ranging from 82.7\% - 98.5\% when tested against material comprising several FMDV serotypes (Chen et al. 2011; Dukes, King \& Alexandersen 2006; Shao et al. 2010). The findings of this study indicate that RT-LAMP is relatively more sensitive than RT-qPCR in the detection of the FMDV 3D(pol) gene.

The RT-LAMP assay used in this study amplified the $3 \mathrm{D}(\mathrm{pol})$ region for $1 \mathrm{~h}$ at $63^{\circ} \mathrm{C}$ whereas real-time RT-PCR took almost $2 \mathrm{~h}$ and $30 \mathrm{~min}$ in a thermocycler. The fact that RT-LAMP takes less time and does not necessarily require a thermocycler implies that there is high potential for its application in the field and in areas where specialised laboratory equipment is not available.

The OP samples analysed during this study were collected from clinically health cattle and African buffalo in livestockwildlife interface areas. It has been reported previously that FMDV detection rates in OP samples are usually low in persistently-infected animals (Vosloo et al. 1996). The sensitivity of RT-LAMP with regard to detecting cases of FMDV that were negative by RT-qPCR (Cq values 32.5-38.5) raises the possibility that the RT-LAMP could be suitable for the identification of animals with persistent FMDV infections and could thus be applied to the surveillance of infectious diseases in Africa in the regions where they are known to be endemic.

As most countries in Africa are planning to adopt a strategic control programme for FMD through vaccination and controlled animal movements, a wider knowledge and

TABLE 2: Summary of results for oesophageal-pharyngeal samples tested during this study.

\begin{tabular}{lllll}
\hline Location & Animal species & Number tested & RT-qPCR positive \\
\hline Tanzania (Katavi NP) & Buffalo & 31 & 15 & RT-LAMP positive \\
& Cattle & 30 & 3 & 18 \\
Malawi (Lengwe NP) & Buffalo & 30 & 4 & 9 \\
& Cattle & 30 & 0 & 3 \\
Mozambique (Marromeu NP) & Buffalo & 29 & 7 & 2 \\
& Cattle & 29 & $\mathbf{2}$ & 5 \\
\hline Total & n/a & $\mathbf{1 7 9}$ & $\mathbf{3 1}$ or $\mathbf{1 7 . 3 \%}$ \\
\hline
\end{tabular}

NP, National Park, n/a, not applicable. 
understanding of the dynamics and epidemiology of FMDV infection should be taken into consideration. This will require the rapid identification of high-risk 'hotspots' as well as potentially-infected and FMD-free zones. This task will, however, need the development of simple and cost-effective diagnostic tools such as RT-LAMP that can be deployed under field conditions in order to identify FMDV infection and to define the spatiotemporal distribution of virus serotypes in the region.

Previous studies have shown the heterogeneity of FMDV serotypes in Southern Africa (Kasanga et al. 2012; Vosloo et al. 2002). This heterogeneity highlights the need for continuous surveillance of FMD using rapid, simple and cost-effective methods that are able to discriminate serotypes and/or subtypes. The RT-qPCR and RT-LAMP assays evaluated during this study could not discriminate serotypes and/ or subtypes, indicating that further research is required in order to develop RT-qPCR and RT-LAMP assays for this purpose, which could then be used in areas of high FMDV heterogeneity.

\section{Limitations of the study}

Possible limitations that could affect the results of the current study include the storage condition(s) of the OP samples and the time taken to transport the samples to the FAO World Reference Laboratory for FMD where the analysis was performed.

\section{Recommendations}

Further in-depth studies are required in order to evaluate the detection ability of RT-LAMP and RT-qPCR on field samples and to compare the performance of the two assays under different conditions such as temperature and moisture.

\section{Conclusion}

In conclusion, we have evaluated the performance of RTqPCR and RT-LAMP assays in the detection of the 3D(pol) region of the FMDV genome from OP probang scrapings. We found that RT-LAMP was superior to RT-qPCR in the detection of FMDV from OP probang samples and could be used for surveillance of FMD in cattle and buffalo in developing African countries.

\section{Acknowledgements}

We thank participating farmers around Katavi, Lengwe and Marromeu National Parks, as well as Gaothlele Thobokwe, for the OP sample collection. This study was supported jointly by the African Development Bank (SADC TADs), the Southern African Centre for Infectious Disease Surveillance (SACIDS) through the Wellcome Trust grant (WT087546MA), the UK Department of the Environment, Food and Rural Affairs (DEFRA) who provided support to the FMD Reference Laboratory through a research project (SE2940) at the Pirbright Institute and the Japan Society for the Promotion of Science by Young Researcher Overseas Visits Program for Vitalizing Brain Circulation. The authors also wish to acknowledge the support provided by the Biotechnology and Biological Sciences Research Council, the Department for International Development and the Scottish Government for their support through the Combating Infectious Diseases of Livestock for International Development initiative (project BB/H009302/1) and European Union FP7-KBBE-2011-5 under grant agreement number 289364 (RAPIDIA-Field) to the Pirbright Laboratory where analysis of samples was performed.

\section{Competing interests}

The authors declare that they have no financial or personal relationship(s) that may have inappropriately influenced them in writing this article.

\section{Authors' contributions}

C.J.K. (Sokoine University of Agriculture) participated in the study design, the experimental work, the analysis and interpretation of the data and drafted the manuscript. W.Y. (University of Miyazaki), V.M (The Pirbright Laboratory) and D.P.K. (The Pirbright Laboratory) participated in the study design, the experimental work and drafting of the manuscript. M.M., J.D., C.M., P.C., L.J. (all Southern African Development Community) and E.R. (Ministry of Livestock Development and Fisheries) participated in sample collection and the writing of the manuscript. P.N.W and M.M.R (both Sokoine University of Agriculture) participated in the study design and the writing of the manuscript. All authors read and approved the final manuscript.

\section{References}

Callahan, J.D., Brown, F., Osorio, F.A., Sur, J.H., Kramer, E., Long, G.W. et al., 2002, 'Use of a portable real-time reverse transcriptase-polymerase chain reaction assay for rapid detection of foot-and-mouth disease virus', Journal of the American Veterinary Medical Association 220(11), 1636-1642. http://dx.doi.org/10.2460/ javma.2002.220.1636

Chen, H.T., Zhang, J., Liu, Y.S. \& Liu, X.T., 2011, 'Rapid typing of foot-and-mouth disease serotype Asia 1 by reverse transcription loop-mediated isothermal amplification', Virology Journal 8, 489. http://dx.doi.org/10.1186/1743-422X-8-489

Dukes, J.P., King, D.P. \& Alexandersen, S., 2006, 'Novel reverse transcription loopmediated isothermal amplification for rapid detection of foot-and-mouth disease virus', Archives of Virology 151(6), 1093-1106. http://dx.doi.org/10.1007/s00705005-0708-5

Kasanga, C.J., Sallu, R., Kivaria, F., Mkama, M., Masambu, J., Yongolo, M. et al., 2012, 'Foot-and-mouth disease virus serotypes detected in Tanzania from 2003 to 2010 Conjectured status and future prospects', Onderstepoort Journal of Veterinary Research 79(2), Art. \#462, 4 pages. http://dx.doi.org/10.4102/ojvr.v79i2.462 Kilkenny, C., Browne, W.J., Cuthill, I.C., Emerson, M. \& Altman, D.G., 2010, 'Improving bioscience research reporting: The ARRIVE guidelines for reporting animal research', PLoS Biol 8(6), e1000412. http://dx.doi.org/10.1371/journal. pbio. 1000412

Knowles, N.J. \& Samuel, A.R., 2003, 'Molecular epidemiology of foot-and-mouth disease virus', Virus Research 91(1), 65-80. http://dx.doi.org/10.1016/S01681702(02)00260-5

Nagamine, K., Hase, T. \& Notomi, T., 2002, 'Accelerated reaction by loop-mediated isothermal amplification using loop primers', Molecular and Cellular Probes 16(3), 223-229. http://dx.doi.org/10.1006/mcpr.2002.0415

OIE (World Organisation for Animal Health, prev. Office International des Epizooties) 2012, Foot and mouth disease, Chapter 21.5. Manual of diagnostic tests and vaccines for terrestrial animals, 7th edn., pp. 145-173, World Organisation for vaccines for terrestrial animal Health, Paris, France.

Parida, M.M., Santhosh, S.R., Dash, P.K., Tripathi, N.K., Saxena, P., Ambuj, S. et al., 2006, 'Development and evaluation of reverse transcription-loop-mediated isothermal amplification assay for rapid and real-time detection of Japanese encephalitis virus', Journal of Clinical Microbiology 44(11), 4172-4178. http:// dx.doi.org/10.1128/JCM.01487-06 
Reid, S.M., Ebert, K., Bachanek-Bankowska, K., Batten, C., Sanders, A., Wright, C. et al fo09, 'Performance of real-time reverse transcription polymerase chain reaction for the detection of foot-and-mouth disease virus during field outbreaks in the
United Kingdom in 2007', Journal of Veterinary Diagnostic Investigation 21(3) 321-330. http://dx.doi.org/10.1177/104063870902100303

Reid, S.M., Ferris, N.P., Hutchings, G.H., Samuel, A.R. \& Knowles, N.J., 2000, 'Primary diagnosis of foot-and-mouth disease by reverse transcription polymerase chain reaction', Journal of Virological Methods 89(1-2), 167-176. http://dx. doi. org/10.1016/S0166-0934(00)00213-5

Reid, S.M., Ferris, N.P., Hutchings, G.H., Zhang, Z., Belsham, G.J. \& Alexandersen S., 2001, 'Diagnosis of foot-and-mouth disease by real-time fluorogenic PCR assay', The Veterinary Record 149(20), 621-623. http://dx.doi.org/10.1136/ vr.149.20.621

Shao, J.J., Chang, H.Y., Zhou, G.Q., Cong, G.Z., Du, J.Z., Lin, T. et al., 2010, 'Rapid detection of foot-and-mouth disease virus by reverse transcription loop-mediated isothermal amplification (RT-LAMP)', International Journal for Applied Research in Veterinary Medicine 8(2), 133-142.
Shaw, A.E., Reid, S.M., Ebert, K., Hutchings, G.H., Ferris, N.P. \& King, D.P., 2007, Implementation of a one-step real-time RT-PCR protocol for diagnosis of footand-mouth disease', Journal of Virological Methods, 143(1), 81-85. http://dx.doi. org/10.1016/j.jviromet.2007.02.009

Vosloo, W., Bastos, A.D., Kirkbride, E., Esterhuysen, J.J., Janse van Rensburg D. Bengis., R.G. et al., 1996, 'Persistent infection of African buffalo (Syncerus caffer) with SAT-type foot-and-mouth disease viruses: Rate of fixation of mutations, antigenic change and interspecies transmission', Journal of General Virology 77(Pt 7), 1457-1467. http://dx.doi.org/10.1099/0022-1317-77-7-1457

Vosloo, W., Bastos, A.D., Sangare, O., Hargreaves, S.K. \& Thomson, G.R., 2002, 'Review of the status and control of foot and mouth disease in sub-Saharan Africa', Revue Scientifique et Technique (International Office of Epizootics) 21(3), 437-449.

Yamazaki, W., Mioulet, V., Murray, L., Madi, M., Haga, T., Misawa, N. et al., 2012, 'Development and evaluation of multiplex RT-LAMP assays for rapid and sensitive detection of foot-and-mouth disease virus', Journal of Virological Methods 192(12), 18-24. 